Y,AK 351

ББК 67.401.11

DOI 10.22394/1682-2358-2017-5-76-83

S.E. Channov, Doctor of Sciences (Law), Professor, Head of the Office and Labor Law Department, Povolzhsky Institute of Management named after P.A. Stolypin, Branch of the Russian Presidential Academy of National Economy and Public Administration

\section{RESPONSIBILITY \\ FOR FAILURES \\ AND ERRORS \\ IN THE STATE \\ INFORMATION \\ SYSTEMS \\ (ON MATERIALS \\ OF JUDICIARY \\ PRACTICE)}

The article analyzes the practice of application of measures of legal responsibility for failures and errors that occur in the functioning of state information systems. The author notes the inconsistency of the judiciary in this matter and proposes to reinforce the principle of responsibility of state bodies and officials for the incorrect functioning of state information systems.

Key words and word-combinations: public management, public information systems, legal liability, property damage.
C.Е. Чаннов, доктор юридических наук, профессор, заведуюший кафедрой служебного и трудового права Поволжского института управления имени П.А. Стольгпина - филиала Российской академии народного хозяйства и государственной служби при Президенте РФ (email:sergeychannov@yandex.ru)

\section{OTВЕТСТВЕННОСТЬ ЗА СБОИ И ОШИБКИ В ГОСУААРСТВЕНHЫХ ИНФОРМАЦИОННЫХ СИСТЕМАХ (по материалам судебной практики)*}

Аннотащия. Анализируется практика применения мер юридической ответственности за сбои и ошибки, возникающие при функционировании государственных информационных систем. Автором отмечается непоследовательность судебных органов в этом вопросе и предлагается закрепить принцип ответственности государственных органов и должностных лиц за некорректное функционирование государственных информационных систем.

Ключевые слова и словосочетания: государственное управление, государственные информационные системы, юридическая ответственность, имущественный ущерб.

И нформационные системы различных типов и назначений с каждым годом приобретают все большее значение и в государственном, и в муниципамьном управлении. ОАновременно растет количество проблем,

* Публикация подготовлена в рамках поддержанного РФФИ научного проекта № 17-03-00082.

76 Bulletin of the Volga Region Institute of Administration • 2017. Vol. 17. № 5 
связанных с их некорректной работой. Программное обеспечение, как и все, созданное человеком, не является совершенным. По статистике, в среднем программа содержит одну ошибку на 1000 строк кода [1, с. 61]. Таким образом, ошибки в программном обеспечении, в том числе используемом при функционировании информаџионных систем, в определенном смысле неизбежность: можно уменьшить их количество, но нельзя их искиючить вообще.

ОАнако если ошибки в информационной системе, используемой гражАанином или организацией исключительно Аля собственных нужА, негативно влияют Аишь на их деятельность, то ошибки и сбои в пубцичных информационных системах, прежде всего государственных, способны, с одной стороны, понизить эффективность государственного управления, а с Аругой - повлечь за собой ущемление прав и свобод граждан. Хрестоматийным остается пример с ЕГАИС (ЕАиной государственной информаџионной системой учета объема производства и оборота этилового спирта, алкогольной и спиртосодержащей продукщии), которая юридически начала свое действие будучи еще абсолютно недоработанной, что повлекло за собой огромный ушерб для участников рынка алкогольной продукщии. Производители и импортеры оџенили свои убытки за 2006 г. в 1 млрА Аомларов недополученной выручки, не считая расходов на обслуживание системы [2, с. 179] (этот факт подтверждается даже на официальном сайте ЕГАИС) [3] .

Сбои и ошибки в различных государственных информационных системах (ГИС) и в настоящее время нередко влекут за собой причинение имущественного ушерба предпринимателям. Кроме того, в последние годы значительно возросло количество случаев привлечения к юридической ответственности (прежке всего административной) физических и юридических лиџ, ненадмежашим образом исполнивших свои обязанности по представлению опредеменной информаџии в ГИС, и ссылающихся при этом на некорректное функционирование указанных систем.

Проблематика ответственности за сбои и ошибки, возникающие при работе ГИС, практически не нашиа отражения в отечественной правовой науке. Как правило, исследователи мишь упоминают о возможных проблемах с использованием ГИС в сфере судебной деятельности [4], таможенного регумирования [5], проведения платежей [6], констатируя, что в таких случаях у участников соответствующих правоотношений могут возникать значительные трудности с реализацией своих прав и обеспечением обязательств.

Из немногих трудов, посвященных изучению правовых последствий ошибок в ГИС, можно выделить статью Р.В. Амелина [7, с. 57], который концентрирует внимание на обязанности государственного заказчика, объявившего конкурс на создание (внеАрение) ГИС, организовать комплексную экспертизу системы на предмет отсутствия ошибок проектирования, а также обязанности вмадельца ГИС, применяемой для автоматизаџии проџессов государственного и муниципального управления, при обнаружении ошибки в системе вывести ее из обращения в той части, в которой эта ошибка влияет на нормативно закрепленный регламент такого процесса. 
Не отрицая необходимости обеспечивать указанные действия в сфере государственного управления, отметим, что в приведенной статье не анализируются именно юридические последствия того, что ошибка (Аибо сбой) в государственной (муниципааьной) информационной системе все же возникми и сушественным образом повмияли на возможность участников правоотношений реализовать свои права и обязанности, что, как указывалось, Ааже при самом тщательном контроле тем не менее является неизбежным.

В рамках Аанной статьи речь пойдет не обо всех правовых последствиях возникновения ошибок и сбоев в ГИС (что требует бомее масштабных исследований), а Аишь об одном ее аспекте: кто и в каких случаях должен нести юридическую ответственность как за необеспечение надмежашего функционирования этих информационных систем, так и за вынужденное (связанное с ненадмежащим функционированием) неисполнение определенных обязанностей.

Отметим, что в судебной практике довольно часто возникают споры, связанные с привлечением физических и юридических миџ, ненадлежащим образом исполнивших свои обязанности по преАставлению опредеменной информации в ГИС в связи со сбоями в их функционировании. Так, уже упомянутая система ЕГАИС и сегодня не отличается стабильностью. Во время круглого стола, посвященного перспективам введения ЕГАИС Аля производителей пива и пивных напитков, прозвучало, что система часто дает сбои, которые устраняются около недели и сказываются на работе, неизбежнны простои предприятий [8] . В то же время, если производитель мибо продавец алкогольных напитков во время сбоя в работе ЕГАИС продолжает осуществлять свою деятельность, он рискует быть привлеченным к административной ответственности.

Так, ООО «Трон» обратилось в Арбитражный суд Чемябинской области с заявлением к Межрегиональному управлению Федеральной служкбы по регулированию алкогольного рынка по Уральскому федеральному округу о признании незаконным и отмене постановления № АП02-2016/288-Ю 2016 г. о привлечении к административной ответственности, предусмотренной ст. 15.13 КоАП РФ, в виде наложения штрафа в размере 50500 рублей.

В данном деле заявитель, не отрицая факта совершения правонарушения, ссылался на отсутствие умысла, мотивируя нарушение срока сАачи деклараџии техническим сбоем автоматизированной информационной системы Федеральной службы по регулированию алкогольного рынка.

Как было установмено судом, обшеством с ограниченной ответственностью «Трон» Аекмарация № 5 об объеме оборота этимового спирта, алкогольной и спиртосодержашей продукции за 2-й квартал 2016 г. преАставлена в административный орган с нарушением срока, установленного законом, на один день. Выявив указанные нарушения, Межрегиональным управлением Федеральной службы по регулированию алкогольного рынка по Уральскому федеральному округу вынесено постановление по делу об административном правонарушении № АП02-2016/288-ЮА от 26 декабря 2016 г. о привлечении к административной ответственности.

Оџенив имеющиеся в материалах дела доказательства, по своему внутреннему убеждению, основанному на их всестороннем, полном, объективном и

78 Bulletin of the Volga Region Institute of Administration • 2017. Vol. 17. № 5 
непосредственном исследовании, суд пришел к выводу о малозначительности административного правонарушения с учетом конкретных обстоятельств дела, отсутствия вредных последствий, незначительный срок нарушения (1 день), и в соответствии с конституџионными принџипами соразмерности и справеАмивости при назначении наказания.

На этой основе суА вынес решение отменить постановление № АПО2-2016/ 288-ЮА от 26 Аекабря 2016 г. о привлечении ООО «Трон» к аАминистративной ответственности, предусмотренной ст. 15.13 КоАП РФ в виде аАминистративного штрафа в размере 50500 рублей [9].

Как виАно, в Аанном случае суА не посчитал сбой в работе ГИС обстоятельством, искиючающим вину предпринимателя. Собственно, он вообще никак не оцениц этот факт, а также его вцияние на возможность исполнения преАпринимателем возложенной на него обязанности. В то же время суА посчитал возможкым признать совершенное правонарушение малозначительным.

В целом при рассмотрении дел об административных правонарушениях, связанных с нарушением обязанности преАставления информации в ГИС, в рамках которых поставщики информации указывают на имевшие место сбои и ошибки, суды вообще часто ссылаются на малозначительность.

Так, ООО «БашРТС» обратилось в Арбитражный суА Республики Башкортостан с заявлением к Государственному комитету Респубцики Башкортостан по тарифам об оспаривании постановцения № 03-06/7-35/16 от 1 марта 2016 г. о привлечении к административной ответственности по ч. 1 ст. 19.8.1 КоАП РФ в виде административного штрафа в размере 100000 рублей.

Решением Арбитражного суда Респубцики Башкортостан от 8 июля 2016 г. заявленные требования удовлетворены, постановление административного органа признано незаконным в связи с малозначительностью деяния. Не согласившись с указанным судебным актом, Комитет обратился в Восемнадцатый арбитражный апемляџионный суА с апеммяџионной жалобой.

Как было установцено судом второй инстанџии, в ходе осуществления плановой выездной проверки ООО «БашРТС» представило материалы по соблюАению организацией стандартов раскрытия информации в сферах теплоснабжения. Проанализировав представленные ООО «БашРТС» материалы в части соблюдения организацией стандартов раскрытия информации в сфере тепмоснабжения, осуществив мониторинг соблюдения организащией стандартов раскрытия информации на официальном сайте Госкомитета, проверяющим органом были выявлены факты несоблюдения ООО «БашРТС» исполнения обязательных требований, установленных п. 9 ст. 7 Федерального закона от 27 июля 2010 г. № 190-ФЗ «О теплоснабжении».

ООО «БашРТС» пояснило, что причиной Аопущенных нарушений являются сбои, несовершенство федеральной государственной информационной системы «ЕИАС Мониторинг». При этом судом было установлено, что ООО «БашРТо» после устранения неполадок программы «ЕИАС Мониторинг» незамеАлительно, до вынесения оспариваемого постановления, раскрыло информацию о плате за подключение с Аифференциацией по размеру подключаемой тепловой нагрузки по диапазонам диаметров и по типу прокладки тепловых сетей. 
Таким образом, по мнению суда второй инстанщии, приведенные обстоятельства в совокупности свидетельствуют об отсутствии со стороны общества пренебрежкительного отношения к исполнению своих пубцично-правовых обязанностей и не влекут сушественной угрозы охраняемым общественным отношениям. На этой основе он постановиц решение Арбитражного суда Республики Башкортостан от 8 июля 2016 г. по делу № А07-7084/2016 оставить без изменения, апемяяционную жалобу Государственного комитета Респубцики Башкортостан по тарифам - без удовметворения [10] .

Обратим внимание: в данном случае, в отличие от предыдущего дела, суА признал, что имелся сбой в работе ГИС, однако также посчитал возможным не привлекать преАпринимателя к административной ответственности в связи с малозначительностью. Отметим, что суды достаточно часто признают наличие сбоев в федеральной государственной информационной системе «ЕИАС Мониторинг, более того, они нередко ссылаются на эти факты как на преюдициальные (см., например, решение Верховного Суда Республики Башкортостан № 21-1355/2016 от 19 октября 2016 г. по Аелу № 21-1355/2016; решение Арбитражного суда Республики Башкортостан от 8 июля 2016 г.), однако при этом, как правимо, освобожАают миц, не исполнивших надмежащим образом обязанности по представлению информации в эту систему, от административной ответственности в связи с малозначительностью. Такой подход преАставляется не совсем верным. Если сбои в информаџионной системе «ЕИАС Мониторинг» Аействительно носят систематический характер и объективно препятствуют нормальной работе с системой, более правильно вести речь об отсутствии вины обязанных киџ в непредставлении информаџии и освобождать их от административной ответственности в связи с отсутствием состава административного правонарушения. То же касается и Аругих ГИС.

Противоположным аспектом рассматриваемой в статье проблемы является вопрос об ответственности государственных органов за сбои и ошибки в работе ГИС, которые создают сложности Аля получения физическими и юридическими миџами различных государственных услуг. На практике такие ситуаџии также нередко имеют место.

Так, ФГУП «Национальные рыбные ресурсы» обратилось в Арбитражный суд Приморского края с заявлением о признании незаконным бездействия Аепартамента земельных и имущественных отношений Приморского края, выразившегося в нерассмотрении заявления от 1 июня 2016 г. № 555/2016/145676 об утверждении схемы расположения земемьного участка; обязании Аепартамент рассмотреть заявление от 1 июня 2016 г. № 555/2016/145676 об утверждении схемы расположения земельного участка; обязании Аепартамента утвердить и выдать схему расположения спорного земельного участка на каАастровом плане территории в отношении земельного участка.

Решением Арбитражного суда Приморского края от 27 декабря 2016 г. в удовлетворении заявленных требований отказано. Не согласившись с вынесенным судебным актом, заявитель обратился в суд с апемяционной жалобой на решение суда первой инстанџии от 27 декабря 2016 г.

Отказывая в удовлетворении заявленных требований, суА первой инстанции исходиц из того, что в действиях Аепартамента отсутствует факт оспари- 
ваемого ФГУП «Нацрыбресурсы» бездействия и нарушения прав и интересов посмеднего.

СУАом второй инстанщии было установлено, что в соответствии с распиской о приеме документов ориентировочной Аатой выдачи итогового документа по предоставлению услуги определено 1 июля 2016 г. Вместе с тем ни 1 июля 2016 г., ни по истечении указанного срока, ни даже на дату обращения заявителя в арбитражный сул с рассматриваемыми требованиями (30 сентября 2016 г.), результаты рассмотрения обращения до заявитемя ФГУП «Нацрыбресурсы» уполномоченным органом доведены не были, а сведения о рассмотрении поданного заявления в соответствии с приведенными нормативными положениями у преАприятия отсутствовали.

Арбитражным судом Приморского края было принято во внимание письмо Аепартамента земельных и имушественных отношений Приморского края № 20/43706 от 20 декабря 2016 г., согласно которому заявление преАприятия поступило в Аепартамент через портал государственных услуг посредством информационной системы «Система исполнения регламентов», в связи с технической невозможностью работы в которой заявление ФГУП «Нацрыбресурсы» было зарегистрировано повторно в региональной межведомственной системе электронного документооборота 27 июня 2016 г., заявлению присвоен номер 20-32873.

Вместе с тем, согласно абзацу 7 п. 6 Положения о государственной информаџионной системе СИР, оператор СИР незамедиительно информирует участников СИР - Аепартамент о сбоях и нарушениях в работе СИР, которые могут повлечь нарушение сроков и качества предоставления государственных функщий. Таким образом, Аепартамент как уполномоченный орган и участник СИР должен был знать о сбоях в работе системы и, следовательно, обязан уведомить заявителя о продлении срока рассмотрения заявления преАприятия. Вместе с тем в материалы дела Аепартаментом такие документы представлены не были.

На этом основании Пятый арбитражный апемяяџионный суА постановил решение Арбитражного суда Приморского края от 27 Аекабря 2016 г. по Аелу № А51-23216/2016 отменить. Признать незаконным бездействие Аепартамента земельных и имушественных отношений Приморского края, выразившееся в нерассмотрении заявления Федерального государственного унитарного предприятия «Национальные рыбные ресурсы» от 1 июня 2016 г. № 555/2016/145676 в установленный законом триАцатидневный срок [11].

Как видно, в Аанном случае суд усмотрел вину государственного органа не в самом факте необеспечения нормального функщионирования ГИС, а в неисполнении обязанности информировать о сбоях в ней. ОАнако о привлечении

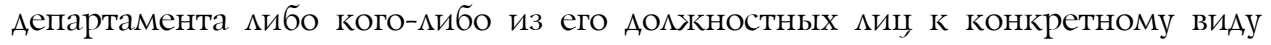
юридической ответственности речь не шла. Иная ситуаџия представлена в следуюшем примере.

В ходе проверки соблюдения законодательства Российской Федерџии о порядке рассмотрения обращений граждан в Головинском отделе судебных приставов УФССП России были выявлены нарушения сроков и порядка регистраџии обращений граждан, которые стали предметом судебного разбирательства по делу № 4а-2660/2014 в Московском городском суде. 
Начальник Головинского отдела судебных приставов УФССП России пытался объяснить допушенные нарушения сбоем в работе ГИС, через которую осуществляется весь документооборот в службе судебных приставов. Он также поясниц, что документооборот ведется только в электронном виде. В итоге обращения граждан, поступившие в периоА сбоя, не регистрировались.

Постановлением мирового судьи судебного участка № 351 района Аэропорт в апреме 2014 г. начальник Головинского ОСП УФССП России был признан виновным в совершении административного правонарушения, предусмотренного ст. 5.59 КоАП РФ, а именно в том, что он нарушиц установленный законодательством РФ порядок рассмотрения обращений граждан, и ему было назначено административное наказание в виде административного штрафа в размере 5 тыс. рубцей.

При этом суА указал, что согласно п. 1.11 Инструкщии по делопроизводству в федеральной службе судебных приставов о случаях нарушения правим работы с документами, установленных инструкщией, государственные служащие структурных подразделений службы в течение одного часа обязаны устно сообщать об этом руководителю структурного подразделения и в управление делопроизводства. По мнению суда, эта обязанность не была исполнена надмежащим образом.

Савеловский районный суд г. Москвы оставил постановление мирового суАьи без изменения, а жалобу Аомжностного миџа - без удовлетворения [12] .

Комментируя принятое решение, Р.В. Амелин пишет, что «данный прецедент весьма показателен, поскольку суд совершенно справедливо учел, что установленная законом обязанность по соблюдению порядка работы с обращениями граждан никак не связана с использованием информационных систем и не может быть поставлена в зависимость от корректной работы последних» [13]. В принципе Аанная позиция заскуживает подсержки. К сожалению, далеко не всегда российские суды признают факт некорректной работы ГИС обстоятельствами, ущемляющими их права.

Так, Верховный СуА РФ отказал в удовцетворении ходатайства о предоставмении отсрочки по уплате государственной пошлины ФГУП «Почта России», которое обратилось в него с кассационной жалобой, одновременно заявив хоАатайство о предоставлении отсрочки по уплате государственной пошлины за рассмотрение кассационной жалобы. В обоснование ходатайства заявитель ссыАался на то, что оплата государственной пошлины на предприятии осуществляется безналичным способом в электронной программе Единой информационной системы казначейства. При оплате государственной пошлины в программе произошел технический сбой на стадии прохождения согласования платежа.

ОАнако, согласно позиџии Верховного СуАа РФ «техническая неисправность оборудования не относится к обстоятельствам, свидетельствующим о невозможности заявителя уплатить государственную пошиину в установценном законом размере» [14] .

По нашему мнению, в настоящее время назрела объективная необходимость решения вопросов распределения ответственности межАу разцичными субъектами правоотношений в случаях ненадмежашего исполнения ими обязаннос- 
тей, вызванного сбоями и ошибками функционирования ГИС. При этом, исходя из того, что использование ГИС в конкретной сфере санкщионируется государством и оно же должно обеспечивать корректное функционирование этой системы, в качестве общего принщипа требуется закрепить освобождение от юридической ответственности физических и юридических кищ, не исполнивших установленную законом обязанность в силу этих сбоев и ошибок. Разумеется, при этом важжно учитывать масштабы и продолжительность сбоев, характер ошибок, а также информацию о том, имелась $\Lambda и$ у Аанного мица возможность исполнить указанную обязанность без использования государственной информаџионной системы.

С Аругой стороны, в случаях если сбои и ошибки в ГИС повлекли за собой ущемление прав физических и юридических миц, в том числе причинение им имущественного ушерба, у указанных мищ должна существовать реальная возможность добиться восстановления прав и привлечения виновных органов и Аолжностных миџ к юридической ответственности.

\section{Библиографический список}

1. Амелин Р.В. Правовое регулирование разработки и внедрения автоматизированных информационных систем в сфере государственного и муниципального управления / под ред. С.Е. Чаннова. М., 2010.

2. Горев А.И. Совместимость информационных систем - новое направление правового регулирования // Эволюция государственных и правовых институтов в условиях развития информационного общества: сборник. М., 2012.

3. Единая государственная автоматизированная информационная система. URL: http://egais-site.ru/

4. Орлов А.В. Обеспечение информационной безопасности судебной деятельности арбитражных судов Российской Федерации // Администратор суда. 2015. № 3. С. 6-10.

5. Денисова А.Ю. Правовое регулирование администрирования таможенных сборов в государствах - членах ЕАЭС // Реформы и право. 2016. № 3. С. 51-63.

6. Белобабченко M.К. Взаимодействие участников платежной системы: вопросы формирования гарантийного фонда // Журнал российского права. 2014. № 10. С. 59-65.

7. Амелин Р.В. Ошибки в АИС в сфере государственного и муниципального управления // Хозяйство и право. 2010. № 2.

8. Российские пивовары против ЕГАИС: пивную отрасль «зарегулировали» // Агропромышленный союз России. URL: http://agro2b.ru/ru/companiesnews/20386-Rossijskie-pivovaryprotiv-EGAIS-Pivnuyu-otrasl.html

9. Решение Арбитражного суда Челябинской области от 19 июня 2017 г. по делу № A761416/2017. URL: https://sudact.ru/arbitral/doc/d1IcdIeLvZZT/

10. Постановление Восемнадцатого арбитражного апелляционного суда от 30 авг. 2016 г. по делу № A07-7084/2016. URL: http://sudact.ru/arbitral/doc/91K7Vjx64Y6j/

11. Постановление Пятого арбитражного апелляционного суда от 10 марта 2017 г. по делу № A51-23216/2016. URL: http://sudact.ru/arbitral/doc/mozldLEJQmgu/

12. Решение Савеловского районного суда г. Москвы от 15 мая 2014 г. № 12-417/14. URL: http://sudact.ru/regular/doc/TBh5y7EDie1v/

13. Амелин Р.В. Правовой режим государственных информационных систем / под ред. C.Е. Чаннова. М., 2016.

14. Определение Верховного Суда РФ от 11 нояб. 2014 г. по делу № 305-ЭС14-5836, А4050680/2013. URL: http://www.consultant.ru/cons/cgi/online.cgi?req=doc\&base $=A R B \& n=410560$ 